\title{
21st International Chromosome Conference-Foz do Iguaçu, Brazil
}

\author{
Erich A. Nigg ${ }^{1}$ Cesar Martins ${ }^{2}$
}

Received: 8 March 2016 / Accepted: 8 March 2016/Published online: 19 March 2016

(C) Springer-Verlag Berlin Heidelberg 2016

International Chromosome Conferences (ICC) can be traced back to the first Oxford Chromosome Conference, organized in 1964 by C.D. Darlington and K.R. Lewis. After evolving into a series of key international conferences, the 21 st edition of the ICC series will for the first time be held in South America, specifically in beautiful Foz do Iguaçu, Brazil, July 10-13, 2016. Organized by Cesar Martins (Brazil), Andrea Pedrosa-Harand (Brazil), Andreas Houben (Germany), Beth Sullivan (USA), Lúcia Martelli (Brazil), and Rachel O'Neill (USA), this meeting will be attended by many renowned speakers and scientists from all around the world (http://www.ibb.unesp.br/icc2016).

Attesting to the importance of ICC for the broad chromosome community, Chromosoma will publish a series of review articles dedicated to the 21 st edition of this conference. The first article by Benavente and colleagues is published in this issue (Fraune et al. 2016) and focuses on the evolution of the mammalian synaptonemal complex. In the next few months, additional ICC-related review articles will continue to highlight recent progress as well as the development of exciting new technologies in chromosome research. Stay tuned!

Erich A. Nigg (Chief Editor Chromosoma)

Cesar Martins (Chair organizing committee, 21st ICC)

\section{Reference}

Fraune J, Brochier-Armanet C, Alsheimer M, Volff J-N, Schücker K, Benavente R (2016) Evolutionary history of the mammalian synaptonemal complex. Chromosoma. doi:10.1007/s00412016-0583-8
Erich A. Nigg

erich.nigg@unibas.ch

1 Biozentrum, University of Basel, Klingelbergstrasse 50/70, 4056 Basel, Switzerland

2 Department of Morphology, Institute of Biosciences, UNESP São Paulo State University, Botucatu 18618-689, SP, Brazil 